\title{
Coordination of Teenagers: A Comparative Study of Municipal and Pastoral Teenagers at Secondary Level in Khyber Pakhtunkhwa, Pakistan
}

\author{
* Bahar Hussain, Lecturer \\ ** Dr. Farooq Hussain, Assistant Professor (Corresponding Author) \\ *** Muhammad Shah, Lecturer
}

\begin{abstract}
This study aims to analyze the coordination ability of Elementary school children 14 to 16 years of age and compare both Postoral and Munciple children of Khyber Pakhtunkhwa (Pakistan). The target population of this study was drawn from primary school children (500) through simple random sampling and the schools were selected through a convenience sample. Two tests Balancing backward (BB) used for measuring the coordination ability of children. The data was collected and analyzed by using SPSS version 22. Both inferential and descriptive statistics had been used for the analysis of data. The data analysis reflects that the students of the Pastoral area had comparatively significantly higher coordination abilities than their counterparts living in municipal areas.
\end{abstract}

Keywords: Coordination, Children, Municipal and Pastoral Sector, BB

Introduction

In the last forty years, studies uncovered an upsurge in rotund and fatness (Hussain, 2018) triggering a decline in bodily strength of individuals that is a major prominent matter and multi-faceted (Mukherjee, Nayek, \& Chatterjee, 2016). The deterioration in the corporeal condition is being observed not only among some factions but the entire culture and environment have deleterious influences on the wellbeing and mentality of the individuals. Bodily strength is deemed crucial for healthiness and well-being (Jeng et al., 2017). Strong cohorts are the properties of a nation while bad physical condition raises expenditure on wellbeing and lessens operating throughput. Hence bodily strength is a trigger of worry for all. Bodily strength is a multi-faceted notion of which skill-associated suitability factor Coordination enjoys an influential position.

Coordination is a powerful bravado and forceful system organizing aptitude which performs motorized movements in a specified moment and location /situation (McArdle, Katch, \& Katch, 2010). The dormant ability or vigor in a part of the body to continue an action in the smallest period over shrinkage and slackening of strengths in the light of coordinative spirited signs/urges is named as Coordination (Karim \& Halim, 2013).

It is believed that the central nervous system (CNS) and peripheral neuromuscular forms and roles have a major influence on Coordination and that it is a function of mental processing. Within the coordination network, it operates under limited and free circulation with stringent moment management (Hohmann, Lames and Letzelter, 2007). Structural and functional components such as intra-muscular harmonization, tension, laziness, and muscle disorder encode the nature of Coordination (Maltais et al., 2014). Besides, Coordination and the concept that determines it are applied and employed in sports events and related theories to provide a drive in which standards are achieved and the response point in time is endured in the shortest feasible time (Schnabel, Harre, and Borde, 1997). When a recurring best Coordination is reached with the capability to withstand the smallest opposition, it is called pace Coordination, such as sprint, jump, tap, etc. Sensitivity can mean that you can react immediately to a stimulus or riot. The adequate response of nerve shrinkage is considered a quantifiable component of velocity grit when an impetus is produced to find the retort (Gratton, Coles \& Donchin, 1992). The velocity movement is the fastest movement achieved in the

\footnotetext{
* Government Degree College, Shewa Swabi Email: baharscope@ gmail.com

** Department of Physical Education and Sports, Abdul Wali Khan University Mardan Email: farooqhussain@awkum.edu.pk

*** Department of Physical Education and Sports, Abdul Wali Khan University Mardan Email: muhammadshah@awkum.edu.pk
} 
shortest time at the least obstacle/resistance. Force, Coordination, and explosive force are forces exerted at such a low resistance (Karim and Halim, 2013)

The CNS, in adolescents between 14and 16 years of age, appears to be expressive and has maximum flexibility. On the one hand, there is a high sensitivity of the nerve manipulation mechanism, and on the other hand, there is a weakened differentiation constraint. This high aptitude is the reason of quick retort, topical frequency affordability, and desired motor learning. The ages of adolescents, in addition to the above, such as (14-16 years), also demonstrate like results (Hollmann $\&$ Hettinger, 1980). Therefore, the crucial findings for the age of 14 to 16 years in adolescents reach a stage of decent response feeling, improvement of Coordination and high-level rate of recurrence to learn a motorized method to build faster movement skills, as well as plain complex (Grosser \& Zintl, 1991). In a Norwegian research paper, Rosvold (2019) found that pastoral adolescents have a higher $\mathrm{VO} 2$ score than municipal adolescents.

For the measurement of Coordination German Motor Test (GMT) Bös, Schlenker, and Seidel (2009) with a Balancing Backward they are widely recognized. In this process, the bodies are exposed to a test with a mandatory remoteness of Balancing Backward. Therefore, an adolescent, who tries two times, must have a space between the two points in the smallest row feasible point in time. According to the rules, an adolescent must remain at the back of the beginning position. A device is employed to observe the start and end signals. When you reach the finish line, the number of steps are measured. The identical line-up is employed for both the start and the end. Besides, two denoting shafts indicate both delineated line-ups (Karim and Halim, 2013). They added that the house or family unit is the basic component of the societal building to examine the connection with promoter skills. Also, Kretschmer and Wirszing (2007) also indicated some places such as parks and other recreation areas where capacity is strongly affected or positively affected. Thus, the objective of the current study is to investigate the level of skill-related fitness component Coordination of Secondary school Teenagers and draw a comparison of Coordination ability between municipal and pastoral Teenagers.

\section{Method}

The German engine test (GMT) developed by Bös, Schlenker, and Seidel (2009) is employed to measure the Coordination of teenagers. All adolescents in municipal and pastoral areas of the Khyber Pakhtunkhwa era, studying at the high school level, make up the population of this study between the ages of 14 and 16. To prepare a sample of teenagers, Krejcie and Morgan (1970) followed a standard sample definition table, and accordingly, 500 adolescents from the looked-for age group was randomly chosen as a sample from the accessible population. The sample was taken from ten government secondary schools in the municipal and pastoral areas. Information received from the Ministry of Education - elementary and secondary was employed to categorize pastoral and municipal institutions. Adolescents from five municipal and five pastoral schools were chosen to take the GMT test. Fifty adolescents from each school participated in the work: ten from each of the stipulated age groups, i.e. ,9 and ten. These adolescents were randomly chosen from grades 9, and 10 from the school attendance registers.

\section{Instruments and Procedures.}

The Balancing Backward test for Coordination measurement was taken from the test item (GMT) of Bös et al. (2009) Measurement of the Coordination ability of adolescents aged 6 to 18 years. This test drive delivers intelligence to quantify the Coordination of teenagers using three balance beams, lawn field, white residue, mark funnel/cover head.

According to the procedure, the adolescent goes through a balance beam. Each adolescent is given two experiments. The adolescent starts from the beginning with the whistle. Each adolescent benefit from the total steps of the two experiments.

The exactness of the hand-stop was effectively tested in this research work. The initiator observed the onset of movement. In the event of an error, execution was stopped immediately and repeated. The collected data were analyzed using version 22 of the Social Scientific Statistical Package (SPSS). Quantitative analytical tools were employed to analyze the data. An independent sample test was employed to assess the average abilities of pastoral and municipal adolescents.

\section{Results}

An examination of the group figures for the Balancing Backward (Table 1.1) shows that the average steps for municipal and pastoral adolescents is 42.17 steps and the standard deviation is 11.14. Municipal adolescents appear to be relatively better (average $=42.70$ steps and SD $=9.65$ ) than 
pastoral adolescents (average $=41.63$ steps and $\mathrm{SD}=12.45)$. Anticipated shift $1.06(\mathrm{SE}=0.99)$. Here again, we are $95 \%$ confident that the actual average variation will remain between -0.8974 and 3.0174 (Table 1.2).

An independent sample test was employed to assess the average of a Balancing Backward (BB) sprint in municipal and pastoral adolescents between 14 and 16 years of age. The p-value is calculated as 0.28 (Table 1.2), which is $>0.05$. Therefore, the variation between the averages of municipal and pastoral residents with $5 \%$ confidence is not significant. The 1.1. The graph also shows the variation in the average completion time of subjects in municipal and pastoral areas in BB.

According to the analysis, the average steps in BB for pastoral adolescents is relatively better (less) than for municipal adolescents, as the variation is analytically substantial. Pastoral adolescents are more compatible with BB associated to municipal adolescents. From the data, it can be deduced that pastoral adolescents are relatively improved in terms of Coordination.

Table 1.1 Group Statistics regarding Coordination

\begin{tabular}{|c|c|c|c|c|c|c|c|}
\hline \multicolumn{2}{|c|}{ Total / Group } & \multicolumn{2}{|l|}{$\mathrm{N}$} & \multirow{2}{*}{$\begin{array}{l}\text { Mean } \\
42.166\end{array}$} & \multicolumn{2}{|c|}{ Std. Deviation } & \multirow{2}{*}{$\begin{array}{l}\text { c.v } \\
26.42 \%\end{array}$} \\
\hline $\mathrm{BB}$ & Total & 500 & & & 11.1400 & & \\
\hline \multicolumn{2}{|c|}{ Postoral } & 250 & & 42.696 & 9.6478 & & $22.60 \%$ \\
\hline \multicolumn{2}{|c|}{ Muncipal } & 250 & & 41.636 & 12.4520 & & $29.90 \%$ \\
\hline \multicolumn{2}{|c|}{ Table 1.2} & \multicolumn{6}{|c|}{ Independent sample t-test for Balancing Backward } \\
\hline \multirow[b]{2}{*}{$\mathrm{T}$} & & & & & \multicolumn{3}{|c|}{$\begin{array}{l}95 \% \text { Confidence } \\
\text { Interval of the Variation }\end{array}$} \\
\hline & df & Sig. (2-tailed) & $\begin{array}{l}\text { Mean } \\
\text { Variation }\end{array}$ & Std. & ariation & Lower & Upper \\
\hline 1.06 & 498 & .288 & 1.0600 & .996 & & -.8974 & 3.0174 \\
\hline
\end{tabular}

Graph 1.1: $\quad$ Graphic description of two means of municipal with pastoral Teenagers

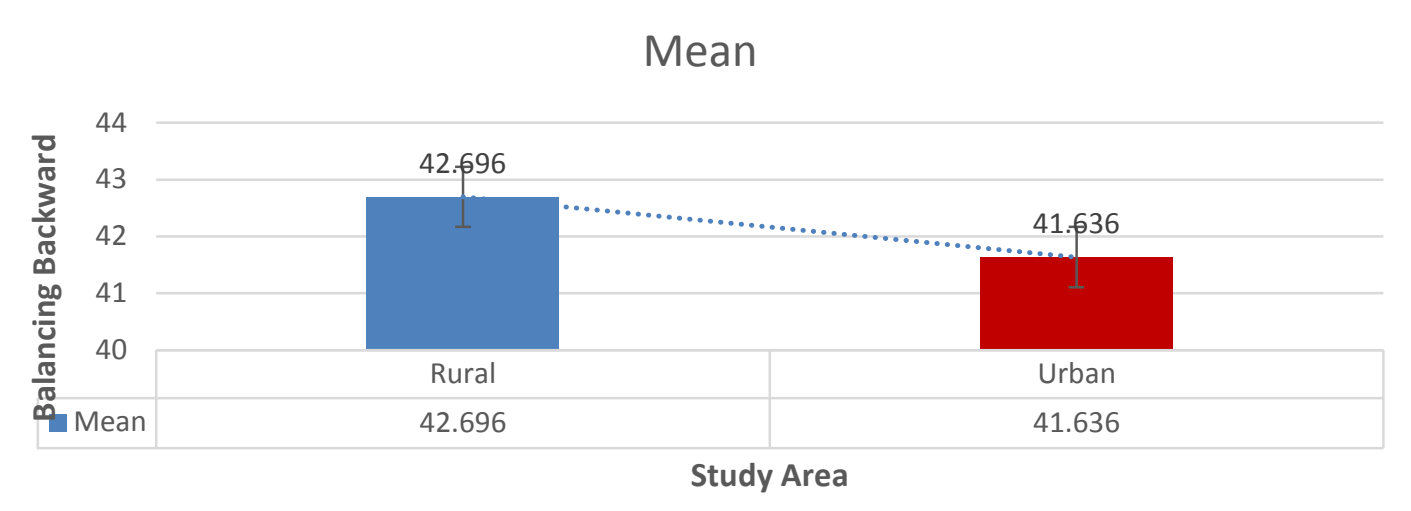

\section{Discussion}

It is reflected by this investigational work that the Coordination disparity between municipal and pastoral teens is substantial. Pastoral teens aged 14-16 was faster than municipal teens. The situation reflects the relatively higher Coordination of pastoral teens as well as the consistency of Coordination, which was also better among their pastoral than municipal counterparts. The remarkable characteristics of municipal and pastoral environments and lifestyles have a positive influence on the Coordination of educating teenagers (de Barros, Fragoso, Oliveira, Cabral Filho, \& Castro, 2003). According to Karim and Halim (2013), the environmental conditions at home or in the family as well as Hussain (2018) are related to the adolescent's abilities in which the adolescent grows. Kretschmer and Wirszing (2007) include places such as parks and other recreational areas, as well as vast areas to facilitate the abilities of teenagers. The ability to Coordination in the present study reflects the impact of the home/family/environment/leisure areas in which the adolescent was raised. According to Rosvold (2019), pastoral teens have a higher VO2 peak than municipal teens. It also supports the dominance of pastoral teens and the weakness of municipal teens. 
These factors could be listed as a standard of living as well as a lifestyle for people living in municipal and pastoral areas. The standard of living consists of nutrition and habits applied in the certain natural setting of the crowds. It is understood that the norm of living in metropolises is typically luxurious, flavored with fast food, rice, meat, and stew. Besides, municipal adolescents do not discover many opportunities to spend their excess dynamism, which can damage their associations, growing their load and bulk. The paucity of leisure places in Khyber Pakhtunkhwa tends to limit their movement, which can act as an unfavorable element of Coordination ability. Huge fields and a pleasant environment also promote the healthy fitness and Coordination of pastoral teenagers. So, all of these factors together support the foundation for low fitness and Coordination in municipal teenagers. However, Coordination, as a component of skill-related fitness, can cause deficiencies in adolescents 'motor skills.

\section{Conclusion}

The mean time value for municipal and pastoral teens is 42.16 steps and the std is 11.14 . The study concluded that the Coordination ability of pastoral teens appears to be better than that of their municipal peers of the same age. Pastoral teenagers appear to outperform in their socio-cultural relationships and in the amount and quality of physical activity that teenagers do inside or outside school. Municipal teenagers deteriorate their bodily strength due to local conditions and practices.

\section{Declaration of Conflicting Interests}

The researcher proclaimed no prospective disagreements of concern relating to the investigational work, authorship, and publication.

\section{References}

Bös, K., Schlenker, L., \& Seidel, I. J. M. T. f. N.-W. D. K. I. f. T. (2009). Deutscher Motorik-Test (DMT 6-18).

de Barros, K. M. F., Fragoso, A. G. C., Oliveira, A. L. B. d., Cabral Filho, J. E., \& Castro, R. M. d. (2003). Do environmental influences alter motor abilities acquisition? A comparison among Teenagers from day-care centers and private schools. Arquivos de Neuro-psiquiatria, 61(2A), $170-175$.

Gratton, G., Coles, M. G., \& Donchin, E. J. J. o. E. P. G. (1992). Optimizing the use of information: strategic control of activation of responses. 121(4), 480.

Grosser, M., \& Zintl, F. (1991). Schnelligkeitstraining: Grundlagen, Methoden, Leistungssteuerung, Programme: BLV.

Hohmann, A., Lames, M., \& Letzelter, M. (2007). Einführung in die Trainingswissenschaft (4. Aufl.): Limpert.

Hollmann, W., \& Hettinger, T. J. N. Y. (1980). Sportmedizin-Arbeits-und Trainingsgrundlagen Stuttgart.

Hussain, B. (2018). Motor Performance Ability of Teenagers: A Comparative Study of Municipal and Pastoral Teenagers at Secondary Level in Khyber Pakhtunkhwa. (MS), Sarhad University of Science and IT Peshawer,

Jeng, S.-C., Chang, C.-W., Liu, W.-Y., Hou, Y.-J., Lin, Y.-H. J. D., \& Journal, H. (2017). Exercise training on skill-related bodily strength in adolescents with intellectual disability: A systematic review and meta-analysis. 10(2), 198-206.

Karim, A., \& Halim, O. M. A. (2013). Motor and cognitive development of selected Egyptian and German Secondary school-aged Teenagers-a cross-cultural study.

Krejcie, R. V., \& Morgan, D. W. (1970). Determining sample size for investigational work activities. Journal of Educational Psychological Measurement, 30(3), 607-610.

Kretschmer, J., \& Wirszing, D. (2007). Mole: motorische Leistungsfähigkeit von Grundschulkindern in Hamburg; Abschlussbericht zum Forschungsprojekt: Jürgen Kretschmer.

Maltais, F., Decramer, M., Casaburi, R., Barreiro, E., Burelle, Y., Debigare, R., . . . medicine, c. c. (2014). An official American Thoracic Society/European Respiratory Society statement: update on limb muscle dysfunction in chronic obstructive pulmonary disease. 189(9), e15e62.

McArdle, W. D., Katch, F. I., \& Katch, V. L. (2010). Exercise physiology: nutrition, energy, and human performance: Lippincott Williams \& Wilkins. 
Mukherjee, S., Nayek, B., \& Chatterjee, K. (2016). A comparative study on skill-related fitness between residential and non-residential schoolboys. International Journal of Physiology, Nutrition \& Physical Education, 1(2), 77-80.

Rosvold, G. (2019). Relation Between Pastoral and Municipal Schools in Regards to Physical Education Participation, Daily Physical Activity and Cardiorespiratory Fitness-A CrossSectional Pilot Study of Norwegian School Teenagers. NTNU,

Schnabel, G., Harre, D., \& Borde, A. (1997). Trainingswissenschaft: Berlin: Sportverlag. 